\title{
Knowledge and Self-Care Practice on Hypertension among Hypertensive Patients in a Tertiary Level Hospital of Kathmandu
}

\author{
Geeta K Satyal', Lalita Rai², Roshani Gautam²,Bhuvan K Dangol², Rajina Shakya ${ }^{3}$ \\ ${ }^{1}$ Female Surgical Ward, Tribhuvan University Teaching Hospital, Maharajgunj, Kathmandu, ${ }^{2}$ Maharajgunj Nursing \\ Campus, Institute of Medicine, Maharajgunj, Kathmandu, ${ }^{3}$ Department of Nursing, Nobel College, Pokhara \\ University, Sinamangal, Kathmandu
}

\section{Corresponding author:}

Geeta Kumari Satyal, BN, MN

Female Surgical Ward, Tribhuvan University Teaching Hospital

Email:gitasatyal@gmail.com

Submitted : 21 Nov, 2019

Accepted : $26 \mathrm{Jul}, 2020$

\begin{abstract}
Introduction

Hypertension is a public health challenge and major risk factor for cardiovascular disease in the developing as well as developed countries. The successful management of hypertension depends upon patient's knowledge on hypertension and self-care practices.

\section{Methods}

A descriptive cross-sectional study was conducted to identify the knowledge and self-care practice on hypertension among 212 hypertensive patients attending in outpatient department of Manmohan Cardiothoracic Vascular and Transplant Center (MCVTC). Non-probability purposive sampling technique was used. Data was collected through face-to-face interview by using structured questionnaire. Data was analyzed using SPSS version 16.0 .
\end{abstract}

\section{Results}

This study showed that $57.5 \%$ of the respondents had adequate level of knowledge on hypertension and $57.1 \%$ of the respondents had good overall self-care practice. Regarding self-care practice, we found $100 \%$ medicine adherence, $85.8 \%$ respondents avoided alcohol and 84.9\% avoided smoking, 50.9\% followed weight management practice, $48.6 \%$ followed dietary management and $44.8 \%$ performed physical activity. Level of knowledge was significantly associated with age, gender, educational status and occupation. Selfcare practice was only significantly associated with educational status. Level of knowledge and self-care practice were significantly positively correlated.

\section{Conclusion}

More than half of the respondents had adequate level of knowledge. Regarding self-care practice, nearly sixty percent of the respondents had good self-care practice. To bring those rates to higher level, awareness programs should be launched about diseases and self-care practice on hypertension.

Keywords: Hypertension, knowledge, self-care practice 


\section{INTRODUCTION}

N on-communicable diseases (NCDs) are creating major health challenges globally. ${ }^{1}$ Cardiovascular disease (CVD) is more common NCDs. It is the number one cause of death globally. More people die annually from CVDs than from any other cause. An estimated 17.7 million people died from CVDs in 2015, representing 31\% of all global deaths. Of these deaths, an estimated 7.4 million were due to coronary heart disease and 6.7 million were due to stroke. Over three quarters of CVD deaths take place in low- and middle-income countries. Out of the 17 million premature deaths under the age of 70 due to non-communicable diseases in $2015,82 \%$ are in low and middle income countries, and $37 \%$ are caused by CVDs. ${ }^{2}$

Hypertension is a chronic condition. It causes coronary heart disease, stroke and other vascular complications. It is the commonest cardiovascular disorder. It is one of the major risk factors for cardiovascular mortality, which accounts for 20-50 percentages of all deaths. ${ }^{3}$

In Nepal, NCDs account for more than $44 \%$ of deaths and $80 \%$ of outpatient contacts. In Nepal, one out of every five individual have hypertension. ${ }^{4}$ In Nepal Overall prevalence of hypertension was $28.9 \%$ (male $28.8 \%$, female $29 \%$ ). The prevalence was increasing with age $(11.1 \%$ in 70 years). According to the seventh report of the Joint National Committee (JNC 7), 29.1\% were in Prehypertensive group. ${ }^{5}$

\section{METHODS}

The study was conducted in outpatient department (OPD) of Manmohan Cardiothoracic Vascular and Transplant Center (MCVTC), Maharajgunj Kathmandu. A descriptive cross-sectional study design was used to assess knowledge and selfcare practice on hypertension among hypertensive patients. The study population was all adult (19 years and above) hypertensive patients diagnosed with hypertension and under the antihypertensive medication for at least six months and willing to participate were included in the study. Non-probability purposive sampling technique was adapted to select sample and face to face interview technique was used to collect data through structured questionnaire. Data was collected from September $2^{\text {nd }}$ to September $28^{\text {th }} 2018$. Before data collection research permission was obtained from Research Committee of Maharajgunj Nursing Campus and ethical approval from Institutional Review Committee (IRC) and hospital administration of MCVTC Maharajgunj. Written Informed consent was obtained from each respondent before taking interview.

For level of knowledge, there were total 13 questions which included single as well as multiple responses with total score ranges from 0-36 and mid value $(50 \%)$ was taken as cut off point. Level of knowledge is adequate above mean and inadequate below mean. To find out the self-care practice, modified pattern of standard tool was used which was Hypertension Self-Care Activity Level Effects (H-SCALE) which consists of six items that is medication, physical activity, dietary pattern, weight management, smoking and tobacco use and alcohol consumption. To identify overall self-care practice, total score was calculated by summing score of six items, where score were awarded for 0-21, physical activity $0-14$, diet score $0-22$, weight management 0-45, alcohol consumption 0-1 and smoking (active and passive) 0-1 respectively, thus total score ranges from 0-104 which was converted into percentile and 75th percentile was taken as cut off point. Good self-care practice $\geq 75 \%$ and Poor self-care practice $<75 \%$. Item wise self-care practice was label as per standard tool.

The collected data was analyzed by using descriptive as well as inferential statistics (Chi square test). Karl Pearson correlation coefficient was used to evaluate relationship between level of knowledge and level of self-care practice. Statistical significance was set at $p$ value $<0.05$.

\section{RESULTS}

This study showed that $35.8 \%$ of the respondents belonged to age group more than 60 and above followed by $27.8 \%$ were age of $51-60$ years with mean age $55.69 \pm 12.46$. More than half $(57.1 \%)$ were female. Almost all (90.6\%) were married, $50.9 \%$ lived in joint family and $62.7 \%$ were residing inside the valley. Two third of the respondents (67\%) were able to read and write and about one third of the respondents $(36.3 \%)$ were home maker and $55 \%$ of the respondents had income enough for $\leq$ 12 months. Nearly half $(48.1 \%)$ of the respondents had family history of hypertension and 107 had associated co-morbidities among them 53.3\% of respondents had diabetes mellitus.

About two-third of the respondents $(60.8 \%)$ had correctly identified normal value of systolic blood pressure and $62.3 \%$ had correctly identified normal value of diastolic blood pressure. In regards to high blood pressure $40.6 \%$ had correctly identified systolic value and nearly half (48\%) had identified high diastolic value of blood pressure. Regarding risk factors majority of the respondents $(69.3 \%)$ replied intake of high salt and high fat diet followed by stress $(65.1 \%)$, increasing age $(40.6 \%)$, intake of excessive amount of alcohol $(30.7 \%)$, use of smoking and tobacco (29.2\%), inactivity (23.1\%) and heredity $(45.3 \%)$ respectively. Majority of the respondents $(69.3 \%)$ had responded headache as major symptoms of hypertension and only $13.7 \%$ 
Table 1. Knowledge regarding hypertension among respondents $(n=212)$

\begin{tabular}{|c|c|c|}
\hline Variables & Number & Percentage \\
\hline \multicolumn{3}{|l|}{ Normal blood pressure } \\
\hline $\mathrm{SBP}(\leq 120 \mathrm{~mm}$ of $\mathrm{Hg})$ & 129 & 60.8 \\
\hline $\mathrm{DBP}(\leq 80 \mathrm{~mm}$ of $\mathrm{Hg})$ & 132 & 62.3 \\
\hline \multicolumn{3}{|l|}{ Hypertension } \\
\hline SBP $(\geq 140 \mathrm{~mm}$ of $\mathrm{Hg})$ & 86 & 40.6 \\
\hline DBP $(\geq 90 \mathrm{~mm}$ of $\mathrm{Hg})$ & 102 & 48.1 \\
\hline Hypertension is controllable & 197 & 92.9 \\
\hline \multicolumn{3}{|l|}{ Risk factors* } \\
\hline High salt and high fat intake & 147 & 69.3 \\
\hline Stress & 138 & 65.1 \\
\hline Heredity & 96 & 45.3 \\
\hline Increasing age & 86 & 40.6 \\
\hline Over weight & 70 & 33.0 \\
\hline Intake of excessive amount & & \\
\hline of alcohol & 65 & 30.7 \\
\hline Smoking and tobacco use & 62 & 29.2 \\
\hline Sedentary life style & 49 & 23.1 \\
\hline \multicolumn{3}{|l|}{ Sign and symptoms* } \\
\hline Headache & 147 & 69.3 \\
\hline Dizziness & 146 & 68.9 \\
\hline Chest heaviness & 51 & 24.1 \\
\hline Fatigue & 46 & 21.7 \\
\hline Bleeding from nose & 31 & 14.6 \\
\hline Asymptomatic & 29 & 13.7 \\
\hline \multicolumn{3}{|l|}{ Diagnostic measures* } \\
\hline Regular health check up & 144 & 67.9 \\
\hline Measurement of BP & 118 & 55.7 \\
\hline $\begin{array}{l}\text { According to symptoms } \\
\text { (perceived by clients such as }\end{array}$ & & \\
\hline headache, dizziness) & 46 & 21.7 \\
\hline \multicolumn{3}{|l|}{ Complications* } \\
\hline Brain attack & 156 & 73.6 \\
\hline Heart attack & 155 & 73.1 \\
\hline Kidney disease & 128 & 60.4 \\
\hline Visual impairment & 121 & 57.1 \\
\hline
\end{tabular}

of the respondents had clamed hypertension had asymptomatic. One third of the respondents $(67.9 \%)$ said hypertension can be diagnosed by regular health checkup. Majority (73.6\%) of the respondents answered brain attack followed by heart attack (73.1\%), kidney disease (60.4\%), and visual impairment $(57.1 \%)$ as the complications of hypertension. Almost all of the respondents (92.9\%) had answered "hypertnesion is disease that is controllable". (Table 1).

Majority of the respondents (89.6\%) had answered intake of prescribed medicine, followed by low salt diet (86.6\%), low fat diet (85.4\%). Majority of the respondents (89.2\%) had answered antihypertensive medication cannot be discontinued (Table 2).
Table 2. Knowledge regarding management of hypertension among respondents $(n=212)$

\begin{tabular}{lcc}
\hline \multicolumn{1}{c}{ Variables } & Number & Percentage \\
\hline $\begin{array}{l}\text { Management } \\
\text { Intake of prescribed }\end{array}$ & & \\
medicine & 190 & 89.6 \\
Intake of low salt diet & 184 & 86.8 \\
Intake of low fat diet & 181 & 85.4 \\
Regular exercise & 133 & 62.7 \\
Management of stress & 116 & 54.7 \\
Quit smoking & 91 & 42.9 \\
Maintain normal weight & 94 & 44.3 \\
Limit alcohol intake & 92 & 43.4 \\
Antihypertensive medicine & & \\
cannot be discontinued & 189 & 89.2 \\
\hline
\end{tabular}

There were $57.5 \%$ of the respondents had adequate knowledge. Regarding self- care practice more than half $(57.1 \%)$ had good self-care practice (Table 3 ).

Regarding item wise self-care practice all the respondents had good practice in intake of medicine, $44.8 \%$ in physical activity, $48.6 \%$ in dietary management, and $50.9 \%$ good practice to control weight, $84.9 \%$ were nonsmoker and $85.8 \%$ were nonalcoholic.

There were significant statistical association with age, gender educational status, occupation and level of knowledge ( $p$ value $=0.001,0.001,0.000$, 0.000 respectively). Respondents with age lower than 65 had better knowledge than those with age equal to or higher than 65. Male respondents had better knowledge than female respondents. Respondents with ability to read and write had higher knowledge than those who could not read and write. The respondents who were homemakers or in agriculture had lower knowledge than the respondents who had different occupations (Table 4).

There is statistical significant association between educational status ( $p=0.006$ ) and level of self-care practice. The respondents with ability to read and write had better self-care practice than those who had no ability to read and write (Table 5).

Table 3. Level of knowledge and self-care practice among respondents $(n=212)$

\begin{tabular}{lcc}
\hline \multicolumn{1}{c}{ Variables } & Number (\%) & Mean \\
\hline Level of knowledge & & \\
Adequate $(\geq 18)$ & $122(57.5)$ & $20.16 \pm 7.44$ \\
Inadequate $(<18)$ & $90(42.5)$ & \\
Level of practice & & \\
Good practice $(\geq 75 \%)$ & $121(57.1)$ & $76.69 \pm 14.08$ \\
Poor practice $(<75 \%)$ & $91(42.9)$ & \\
\hline
\end{tabular}


Table 4. Association between level of knowledge on hypertension among respondents and selected variables

\begin{tabular}{|c|c|c|c|c|c|}
\hline & \multirow[b]{2}{*}{ Variables } & \multicolumn{2}{|c|}{ Level of knowledge } & \multirow[b]{2}{*}{ Chi-square } & \multirow[b]{2}{*}{$\mathrm{p}$-value } \\
\hline & & $\begin{array}{c}\text { Inadequate } \\
\mathrm{n}(\%)\end{array}$ & $\begin{array}{l}\text { Adequate } \\
\text { n (\%) }\end{array}$ & & \\
\hline Age & $\begin{array}{l}\leq 45 \text { years } \\
45-64 \text { years } \\
\geq 65 \text { years }\end{array}$ & $\begin{array}{l}11(26.8) \\
40(37) \\
39(61.9)\end{array}$ & $\begin{array}{l}30(73.2) \\
68(63) \\
24(38.1)\end{array}$ & 15.151 & $0.001 *$ \\
\hline Gender & $\begin{array}{l}\text { Male } \\
\text { Female }\end{array}$ & $\begin{array}{l}27(29.7) \\
63(52.1)\end{array}$ & $\begin{array}{l}64(70.3) \\
58(47.9)\end{array}$ & 10.663 & $0.001 *$ \\
\hline Educational status & $\begin{array}{l}\text { Able to read and write } \\
\text { Cannot read and write }\end{array}$ & $\begin{array}{l}45(31.7) \\
45(64.3)\end{array}$ & $\begin{array}{l}97(68.3) \\
25(35.7)\end{array}$ & 20.391 & $0.000 *$ \\
\hline Occupation & $\begin{array}{l}\text { Homemaker and agriculture } \\
\text { Other than homemaker and } \\
\text { agriculture }\end{array}$ & $\begin{array}{l}58(55.8) \\
32(29.6)\end{array}$ & $\begin{array}{l}46(44.2) \\
76(70.4)\end{array}$ & 14.818 & $<0.001^{*}$ \\
\hline Type of family & $\begin{array}{l}\text { Nuclear } \\
\text { Joint }\end{array}$ & $\begin{array}{l}48(46.2) \\
42(38.9)\end{array}$ & $\begin{array}{l}56(53.80) \\
66(61.10)\end{array}$ & 1.145 & 0.26 \\
\hline $\begin{array}{l}\text { Family history of } \\
\text { hypertension }\end{array}$ & $\begin{array}{l}\text { Yes } \\
\text { No }\end{array}$ & $\begin{array}{l}43(42.2) \\
47(42.7)\end{array}$ & $\begin{array}{l}59(57.8) \\
63(57.3)\end{array}$ & 0.007 & 0.93 \\
\hline
\end{tabular}

This study shows that there is positive relationship between knowledge and practice at $95 \%$ of confidence level ( $r=0.209 ; p$ value=0.002). The participants who had better knowledge of the disease had better self-care practice.

\section{DISCUSSION}

The current status of knowledge on hypertension was adequate in more than fifty percent (57.5\%) of the respondents and $57.1 \%$ had good self-care practice on hypertension. In this study, about two third of the respondents (60.8\%) had correctly identified normal value of systolic blood pressure and $62.3 \%$ had correctly identified normal value of diastolic blood pressure. In high blood pressure, only $40.6 \%$ had correctly identified systolic value while nearly half (48\%) had identified high diastolic value of blood pressure. The finding of the study contradicts the result shown by Patnaik et al.,6 in India which revealed that $34.7 \%$ were not aware about the normal blood pressure range and $53.9 \%$ had no idea about systolic and diastolic blood pressure.

Table 5. Association between level of knowledge on self care practice among respondents and selected variables

\begin{tabular}{|c|c|c|c|c|c|}
\hline & \multirow[b]{2}{*}{ Variables } & \multicolumn{2}{|c|}{ Level of practice } & \multirow[b]{2}{*}{ Chi-square } & \multirow[b]{2}{*}{$p$-value } \\
\hline & & $\begin{array}{l}\text { Inadequate } \\
\mathrm{n}(\%)\end{array}$ & $\begin{array}{l}\text { Adequate } \\
\mathrm{n}(\%)\end{array}$ & & \\
\hline Age & $\begin{array}{l}\leq 45 \text { years } \\
45-64 \text { years } \\
\geq 65 \text { years }\end{array}$ & $\begin{array}{c}25(61) \\
53(49.1) \\
39(61.9)\end{array}$ & $\begin{array}{c}16(39) \\
55(50.9) \\
24(38.1)\end{array}$ & 3.337 & 0.19 \\
\hline Gender & $\begin{array}{l}\text { Male } \\
\text { Female }\end{array}$ & $\begin{array}{l}49(53.8) \\
68(56.2)\end{array}$ & $\begin{array}{l}42(46.2) \\
53(43.8)\end{array}$ & 0.116 & 0.73 \\
\hline Marital status & $\begin{array}{l}\text { Married (living with spouse) } \\
\text { Single(unmarried, widow, } \\
\text { divorced) }\end{array}$ & $\begin{array}{l}103(53.6) \\
14(70)\end{array}$ & $\begin{array}{c}89(46.4) \\
6(30)\end{array}$ & 1.959 & 0.16 \\
\hline Educational status & $\begin{array}{l}\text { Able to read and write } \\
\text { Cannot read and write }\end{array}$ & $\begin{array}{l}69(48.6) \\
48(68.6)\end{array}$ & $\begin{array}{l}73(51.4) \\
22(31.4)\end{array}$ & 7.568 & $0.006^{*}$ \\
\hline Economic condition & $\begin{array}{l}\text { Income enough } \leq 12 \text { months } \\
\text { Income enough } \geq 12 \text { months }\end{array}$ & $\begin{array}{l}73(62.4) \\
44(43.6)\end{array}$ & $\begin{array}{l}44(37.6) \\
51(53.7)\end{array}$ & 5.480 & 0.19 \\
\hline $\begin{array}{l}\text { Family history of } \\
\text { hypertension }\end{array}$ & $\begin{array}{l}\text { Yes } \\
\text { No }\end{array}$ & $\begin{array}{c}52(51) \\
65(59.1)\end{array}$ & $\begin{array}{c}50(49) \\
45(40.9)\end{array}$ & 1.408 & 0.24 \\
\hline
\end{tabular}


Regarding knowledge about risk factors of hypertension, we found that majority $(69.3 \%)$ of the respondents replied intake of high salt and high fat diet followed by stress $(65.1 \%)$, increasing age $(40.6 \%)$, intake of excessive amount of alcohol $(30.7 \%)$, inactivity $(23.1 \%)$ and heredity $(45.3 \%)$. The present study finding is consistent with study done in India by Patnaik et al., ${ }^{6}$ which revealed that majority $(61.8 \%)$ of the respondent had answered increased salt intake followed by $52 \%$ heredity, $43 \%$ no regualr exercise, $39.2 \%$ tobacco used and $28.4 \%$ alcohol consumption.

Knowledge on sign and symptoms of hypertension revealed that majority of the respondents $(69.3 \%)$ replied headache followed by (68.9\%) as dizziness, $(21.7 \%)$ as fatigue, $(14.6 \%)$ as bleeding from nose, $(24.1 \%)$ as chest heaviness and (13.7\%) answered there were asymptomatic. The finding of this study is supported with study done by Adebayo et al., ${ }^{7}$ where $77.5 \%$ of the respondents had answered headache followed by $56.4 \%$ as chest pain, $55.6 \%$ as dizziness, $43.6 \%$ as blurring of vision, $39.3 \%$ as difficulty in breathing and only $17.1 \%$ had answered there were asymptomatic.

Regarding complications, we found that $73.6 \%$ had answered paralysis, $73.1 \%$ answered heart attack, 60.4\% answered kidney disease and $57.1 \%$ answered visual impairment. This finding is consistent with Adebayo et al., ${ }^{7}$ which found that $84 \%$ of the patients had stated stroke, followed by $66.5 \%$ as paralysis, $50.5 \%$ as kidney failure, $37.8 \%$ as blindness and $69.5 \%$ as death as the complications of hypertension.

We found that for managing of hypertension, most of the respondents (89.6\%) had answered intake of prescribed antihypertensive medicine, $86.8 \%$ replied intake of low salt diet, $62.7 \%$ stated regular exercise, $44.3 \%$ told weight reduction, $54.7 \%$ stated reduction of stress, $42.9 \%$ stated quit smoking and $43.4 \%$ stated limiting intake of alcohol. The findings of the study is similar with study findings of Kisokanth et al., ${ }^{8}$ where $81.1 \%$ stated intake of low salt diet, $75.7 \%$ weight reduction, $45.5 \%$ regular physical exercise, $47.9 \%$ quit smoking and $46.9 \%$ stated restriction of alcohol to manage hypertension. In this study most of the respondents (89.2\%) had answered antihypertensive medication cannot be discontinued. This study finding is supported by Bhandari et al., ${ }^{9}$ where $70 \%$ of the respondents had answered antihypertensive medicine cannot be discontinued.

In this study all the respondents took blood pressure pills every day at the same time as recommended number of blood pressure pills. The finding of the study is supported by the study done by Karmacharya and Poude ${ }^{10}$ where almost $85 \%$ of the respondents took medication regularly. This finding was lower in percentage (i.e. $58.6 \%$ ) of medication adherence in study conducted by Warren-Findlow and Seymour ${ }^{11}$. In this study, $44.8 \%$ of the respondents were involved in regular physical exercise for at least 30 minutes everyday. Similar findings to the study done by Warren-Findlow and Seymour ${ }^{11}$ where $(52.2 \%)$ were engaging in physical activity and some exercise on most days of the week. This study finding contradict with study done by Zinat Motlagh et al., ${ }^{12} 24.5 \%$ engaged in physical activity most of the days in a week. This study showed that $92 \%$ of the respondents had not used additional salt in their food while eating and only $8 \%$ of the participant had used additional salt while eating. More than half $(51.4 \%)$ of the respondents had consumed processed food daily. The study by Dasgupta et al. ${ }^{13}$ showed similar finding- $48 \%$ of the respondents always tried to avoid adding extra salt in their food. This study finding differ from the study done by Kisokanth et al., ${ }^{8}$ which showed that $2.6 \%$ of the respondents consume pickle daily. We found that $14.2 \%$ consumed alcohol and $11.3 \%$ had used tobacco. This finding contradicts with study done by Zinat Motlagh et al., ${ }^{12}$ in Iran- none of the participants consumed alcohol. This finding aligns with Bhandari et al., ${ }^{9}$ where $16 \%$ of the participant consumed alcohol.

\section{CONCLUSION}

Based on the findings of the study, it can be concluded that more than half of the respondents have adequate level of knowledge. Regarding selfcare practice nearly sixty percent of the respondents have good self-care practice. Still health care institution needs to have provision of awareness program about disease and self-care practice on hypertension.

\section{CONFLICT OF INTEREST}

None declared.

\section{ACKNOWLEDGEMENT}

The authors are thankful for the support provided by University Grant Commission, TU, IOM, IRC, Mahararajgunj Nursing Campus, Manmohan Cardiothoracic Vascular and Transplant Centre. Authors are grateful to Assoc. Prof. Jan WarrenFindlow, Mr. Bibhav Adhikary, all the participants and all people who helped in this study possible.

\section{REFERENCES}

1. Nepal Health Research Council. Non Communicable Diseases Risk Factors: STEPS Survey Nepal 2013. Kathmandu: Nepal Health Research Council. Available at: https://www.who.int/ncds/ surveillance/steps/2012-13_Nepal_STEPS_Report.pdf.

2. World Health Organization. Non Communicable Diseases. World Health Organization; 2018. Available at: https://www.who.int/ news-room/fact- sheets/detail/noncommunicable-sheets/detail/ noncommunicable-diseases. 
3. Park K. A Textbook of Preventive and Social Medicine. Twenty Fifth Edition. Prem Nagar, Nagpur Road, Jabalpur, India; 2015.

4. Hasan M, Sutradhar I, Akter T et al. Prevalence and Determinants of Hypertension Among Adult Population in Nepal: Data from Nepal Demographic and Health Survey 2016. PloS One. 2018 May 31; 13(5):e0198028.

5. Koju R, Manandhar K, Gurung R et al. Prevalence of Hypertension in Semi-Urban Area of Nepal. NHJ. 2010;7(1):35-9.

6. Patnaik L, Paul KK, Pattnaik $S$ et al. Lifestyle Pattern and Hypertension Related Knowledge, Attitude and Practices Among Diagnosed Patients of Hypertension Attending a Tertiary Care Hospital. J Cardiovasc Dis Res.2017Nov3; 8(4):108-11.

7. Adebayo A. M, Rotkangmwa O. C, \& Shalkur D. An Assessment Of Hypertension Related Knowledge Levels Among Hypertensive Patients Attending Tertiary Health Care Facilities. World I Pharm Sci. 2015; 3(2):368-375.

8. Kisokanth G, Ilankoon IM, Arulanandem K et al. Assessment of Knowledge on Hypertension, its Consequences and Management Practices Among Hypertensive Patients-A Descriptive Study. Journal of the Postgraduate Institute of Medicine. 2016 Nov 24;3.

9. Bhandari $B$, Bhattarai $M, B$ Bhandari $M$ et al. Awareness of Disease and Self-Care Among Hypertensive Patients Attending Tribhuvan University Teaching Hospital, Kathmandu, Nepal. Journal of Nobel Medical College. 2011;1(2):29-35.

10. Karmacharya R, Paudel K. Awareness on Hypertension and Its SelfManagement Practices Among Hypertensive Patients in Pokhara, Western Nepal. Janapriya Journal of Interdisciplinary Studies. 2017;6:110-20.

11. Warren-Findlow J, Seymour RB. Prevalence Rates of Hypertension Self-Care Activities Among African Americans. I Natl Med Assoc.2011 Jun ;103(6):503-12.

12. Motlagh SF, Chaman R, Sadeghi E et al. Self-care Behaviors and Related Factors in Hypertensive Patients. Iranian Red Crescent Med. J.2016 Jun;18(6).

13. Dasgupta A, Sembiah S, Paul B et al. Assessment of Self-Care Practices Among Hypertensive Patients: A Clinic Based Study in Rural Area of Singur, West Bengal. Int I Community Med Public Health. 2017;5(1):262-7. 